\title{
Factors that Influence Farmers' Participation in Soil and Water Conservations in Farta Woreda, South Gondar Zone of Amhara National Regional State, Ethiopia
}

\author{
Delelegn Adugna $^{1 *}$ Dr. Daregot Berihun ${ }^{2}$ Hailu Menale ${ }^{3}$ \\ 1. Amhara National Regional State Bureau of Agriculture \\ 2. Department of Economics, Bahir Dar University \\ 3. Guna Tana Integrated Field Research and Development Centre, Debre Tabor University
}

\begin{abstract}
Soil water conservation activities have an impact on food security. However, extent of participation in soil water conservation depends on the extent of farmers' participation. The objective of this study was to examine factors that influence farmers' participation in soil and water conservation activities. Primary and secondary data were used for this research and primary data were collected using pre-tested structured questionnaire. A two stage sampling procedure was employed to select sample households. In the first stage 6 sample kebeles was selected out of 41 kebelas and in the second stage from 8230 households, 381 sample households was selected through a simple random sampling. Descriptive statistics and binary logistic regression model was employed to identify factors that affect farmers' participation in soil and water conservation. The result of binary logit model revealed variables such as family size, education level, livestock holding and size of cultivated land were significant factors that affect farmers' participation in soil and water conservation activities.
\end{abstract}

Keywords: Participation, Soil and Water Conservation, Binary Logistic Regression

DOI: $10.7176 / \mathrm{JNSR} / 12-15-01$

Publication date:August $31^{\text {st }} 2021$

\section{Introduction}

One of the most serious problems currently affecting agricultural productivity in developing countries is land degradation (Oluwole Matthew and Ejovwoke UMUKORO, 2011; Kouelo Alladassi,et.al. 2015). Land degradation, defined as a temporary or permanent decline in the productive capacity of land, or its potential for environmental management, which significantly contribute to the low level productivity of crop and livestock (Bezuayehu Tefera et.al. 2002). Soil erosion is the main form of land degradation, caused by the interacting effects of factors, such as biophysical characteristics and socio-economic aspects (Amsalu and de Graaff, 2006, Adugna et al., 2015). It is a complex process that involves the detachment, movement and deposition of soil particles mainly by wind and water which may accelerated by human activities such as deforestation, intensive grazing, and settlement, but also by natural conditions, with topography (slope angle and slope length) and soil properties (texture, structure, moisture, roughness, and organic matter) (Sui et al., 2009).

In sub-Saharan African, Ethiopia is one of the most well-endowed countries in terms of natural resources (Gete et al. 2006). However, natural resource degradation has been going on for centuries due to soil erosion and erosion is prevalent at a tragic rate in the country (Abera Birhanu, 2003; Hurni et al. 2010). Rapid rate of soil erosion had become a key issue on the livelihood resource in the country, resulted for food insecurity and even difficult to break through the poverty gap using subsistence farming (Tesfa Worku and Sangharsh Kumar, 2016). Rapid population increment, deforestation, low vegetative cover and unbalanced crop and livestock production combined with topography, soil types are the major cause for soil erosion in the country (Girma 2001; Paulos 2001). High rate of population growth in the country is the root cause for this high level soil erosion as it increases natural resource uses demand that can aggravate soil erosion. According to Berry (2003) land resource productivity is an important problem in Ethiopia and that with continued population growth, the problem is likely to be even more important in the future. This indicate the need of soil water conservation intervention.

Nigussie et.al.(2019) conduct paper review about Ethiopia's experience and research progress in past soil and water conservation efforts. According to the review, although indigenous soil water conservation in the country date back to $400 \mathrm{BC}$ institutionalized soil water conservation activity became significant only after the $1970^{\text {th }}$. However, soil water conservation has still a number of barriers including poor community participation. This poor community participation may come from their perception regarding to the importance of soil water conservation practices. Hence, it is important to identify factors which influence farmers' participation in soil and water conservation practices in order to fill the gap and being effective in conservation practices.

\section{Methodology}

This study was conducted in Farta Woreda, Amhara National Regional State, Ethiopia which located between $11^{1} 32^{\prime}-12^{\circ} 03^{\prime}$ latitude and $37^{0} 31^{\prime}-38^{\circ} 43^{\prime}$ longitude. The Woreda is divided into 41 local administrations called 
Kebela and has a total area of 111788 hectare. There is high altitudinal gradient difference in the study area with a range from 1900 to 4113 m.a.s.l. and it has different topography. The topography and a terrain consists of $45 \%$ gentle slope, $29 \%$ flat and $26 \%$ steeply sloped. Regarding to agro-climatic zone, the area is divided in to two, which are dega and woinadega. Dega consists an area with altitude more than 2300 m.a.s.l. and it covers about $44 \%$ of the area. Woinadega ranging between 1900-2300 m.a.s.l and covers about $56 \%$ of the area. Unimodal is the rainfall pattern of the area with a mean annual rainfall of $1570 \mathrm{~mm}$ and it has $15.5^{\circ} \mathrm{c}$ mean annual temperature (FWOA, 2013).

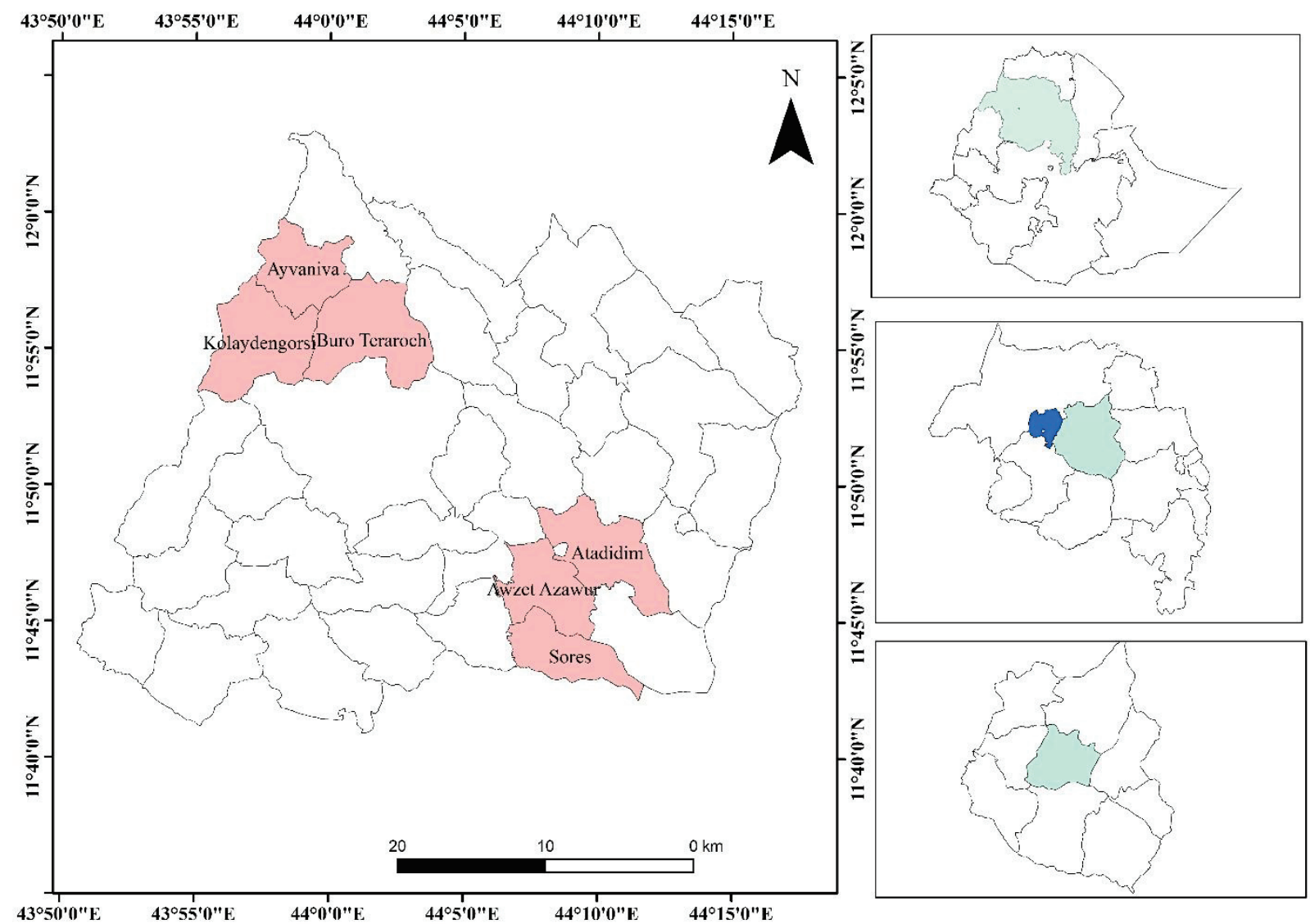

Fig. 1 Map of the study site

Quantitative and qualitative data were collected for the study from primary and secondary sources. Primary data was collected from sample households. Two stage sampling procedure was used to select sample. Out of 41 kebelas 3 kebeles from highland and 3 kebeles from mid-altitude a total of 6 kebelas, which has 8230 households, were selected in the first stage and in the second stage sample households were determine using a "simplified formula for proportions" which was provided by Yamane (1967:886) cited in Endalamaw, 2013 was used : $\boldsymbol{n}=\frac{\boldsymbol{N}}{1+\mathrm{N}(e)^{2}}$

Where:

$\mathbf{n}=$ statistically acceptable sample size

$\mathbf{N}=$ total household size of the sample kebeles i.e 8230

$\mathbf{E}=$ level of precision (error level) at $95 \%$ confidence level (0.05)

$$
\mathbf{n}=\underline{\mathbf{8 2 3 0}}
$$

$1+8230(0.05)^{2}$

Hence, the total households which are living in the six sample kebeles for this study was 8230 . Using this formula, statistically acceptable sample size from the given HHs with maintaining a 95\% confidence level is found to be $\mathbf{3 8 1}$ household heads for the study. Then sample HHs were randomly selected using probability proportional to sample size sampling techniques. The list of household heads in each kebeles was used to make random selection of the sample household farmers. The random was started at household number 5 and the next households were selected at random interval of 22 by chance from each kebele.

A structured questionnaire was used to collect primary data on household demographic characteristics and participation in SWC. The structured survey questionnaire was pre-tested before the actual data collection and some adjustments were made after the pre-test based on the results. Five enumerators who can speak the local 
language were trained on the techniques of data collection, including how they should approach farmers, conduct the interview, and convince the respondent to give relevant information on sensitive economic and social issues. Continuous assistance was made by the researcher to correct possible errors at the field and more than half of the data were collected by researcher. The survey was conducted from the mid March to the early April 2014.

In the study, participation of households' in SWC was examined. Participation of households in SWC activities (PSWC) was considered as dependent variables. It is a dichotomous variable in the model taking value of 1 if a household head participates in any of SWC activities (in bunds, cut-off-drains and waterway, check dam construction, plantation on physical conservation structures and area closure) in terms of labor and finances or both and 0 otherwise. It was expected to be influenced with the following explanatory variables.

Different explanatory variables which were expected to affect participation of households in SWC activities were also selected based on literatures and personal knowledge of the researcher about the study area. Age of the household head (AGE), Family size of the household (FAS), Education level of the household head (EDU), Number of livestock owned (TLU), Cultivated farm land (CFL) and Extension contact (EXC) are variables which were selected for the study. Activities of SWC such as bunds, cut-off-drains and waterway, check dam construction, plantation on physical conservation structures and area closure that expected to increase productivity and reduce food insecurity were considered to assess the extent of farmers' participation towards the technology. Farmers' participation level in soil and water conservation was given a value as participation index formula. Participation index of individual farmer was calculated using formula provided by (Badal, et al. 2006) as.

Where,

$$
\mathbf{P I}_{\mathrm{j}}=\frac{\Sigma_{\mathrm{j}}^{\mathrm{N}} \mathrm{x}_{\mathrm{j}}}{\mathrm{N}}
$$

$\mathbf{P I}_{\mathbf{j}}=$ Participation Index for the $i^{\text {th }}$ farmer

$\mathbf{X}_{\mathrm{j}}=1,2,3-\mathrm{N}$ activities used to indicate the participation of $\mathrm{i}^{\text {th }}$ farmer in SWC

$\mathbf{N}=$ Total number of activities taken to indicate participation level (bunds, cut-off-drains and waterway, heck dam construction, plantation on physical conservation structures, area closure etc.)

Functional relationship of dependent and independent variables, selection of analytical model to identify factors that affect dependent variables, regression technique produces as well as parameter estimation of the model were used as data analysis technique which explained as follow:

Functional form of models: The functional relationship of the dependant variables (household's participation in SWC activities and food security status) and explanatory variables was illustrated as follows:

\section{PSWC $=$ f $\{$ AGE, FAS, EDU, TLU, CFL, EXC $\}$}

Where: PSWC $=$ a dependant variable which is binary $(0,1)$ for household's participation in SWC activities, and Independent variables: Where: $\mathrm{AGE}=$ is a continuous variable designating age of the household head, FAS = is a continuous variable designating the size of the household, EDU = is a continuous variable designating the educational attainment of the household head TLU $=$ is a continuous variable designating for total livestock owned, $\mathrm{CFL}=$ is a continuous variable which represents the size of cultivated farm land in hectare, $\mathrm{SFP}=$ is a dummy variable taking value 1 if the farmer faced soil fertility problem; 0, otherwise $\mathrm{EXC}=$ is a continuous variable designating number of visit per a year that the household head from development agents (DAs) to get extension service.

Analytical econometric model selection: When the dependent variable is binary $(0,1)$, OLS regression technique produces parameter estimates that are inefficient and heteroscedastic error structure. As a result, testing hypothesis and construction of confidence interval becomes inaccurate and misleading (Aldrich and Nelson, 1984) cited in Hlina 2005. Similarly, a linear probability model may generate predicted value outside 0 1 interval which violates the basic tenets of probability. It also creates a problem of non- normality of the disturbance term (Ui), hetroscdasticity of Ui, possibility of $\hat{y}$ lying outside the $0-1$ range and the generally lower $\mathrm{R}^{2}$ values. As result hypothesis testing and constructing confidence interval become inaccurate and misleading and moreover the predicted values ( $\hat{y}$ ) lies outside $0-1$ range and violate the basic tenets of probability (Gujarati, 2004). To alleviate these problems and produce relevant outcomes, the most widely used qualitative response models are the logit and probit models (Amemaya, 1981) cited in Hilina 2005.

The logit and probit are the possible alternative models and have been widely used for a binary response variable which give qualitatively similar results. However, logit model extremely flexible and easily used model from mathematical point of view and results in meaningful interpretation than probit model. (Gujarati, 2004) Therefore in this study binary logistic regression model was employed to analyze both factors that affect farmers' participation in SWC activities.

Binary logistic regression model: Binary logistic model was used to identify factors that affect farmers' participation in SWC activities to assess their relative importance in determining the participant in SWC activities. The analysis of the logistic regression model was showed that changing an independent variable alters 
the probability that a given individual becomes participant in SWC activities and was helped to predict the probability being participant in SWC activities.

Following Gujarati (2004), the functional form of logit model was specified as follows:

$$
\mathrm{P}_{\mathrm{i}}=\frac{1}{1+e^{-Z i}}
$$

Where, $\mathrm{P}_{\mathrm{i}}$, is the probability that a given household be participant in SWC activities.

$\mathrm{Zi}$ : is a function of $\mathrm{n}$ - explanatory variables $(\mathrm{x})$ and expressed as:

$\mathrm{Z}_{\mathrm{i}}=\beta_{\mathrm{e}}+\beta_{1} X_{i 1}+\beta_{2} X_{i 2}+\cdots+\beta_{n} X_{i n}$

Where:

Bo: is the intercept.

$\mathrm{B} 1, \mathrm{~B} 2, \ldots \mathrm{Bn}$, are coefficients of the equation in the model.

The slopes tell how the log-odd in favor of household is participant in SWC activities as independent variables change.

$\mathrm{Pi}$ is not only non-linear in $\mathrm{X}$ but also in the Bi's, which can be written as:

$$
\mathrm{pi}=\frac{1}{1+e^{-\left(\beta_{0}+\beta_{1} X_{i 1}+\beta_{2} X_{i 2}+\cdots \beta_{n} X_{i n}\right)}}
$$

The probability that a given household be non participant is expressed by:

$1-\mathrm{P}_{\mathrm{i}}=\frac{1}{1+{ }_{\theta} Z_{i}}$.

Therefore, taking the ratio of the probability household is participant to nonparticipant in SWC activities can be written as:

$$
\frac{\mathrm{P}_{1}}{1-\mathrm{P}_{1}}=\frac{1+e^{Z_{i}}}{1+e^{-Z_{i}}}=e^{Z_{i}}
$$

Now $\frac{\mathbf{P}_{i}}{\mathbf{1}-\mathbf{P}_{i}} \quad$ is simply the odds ratio in favor of participant to nonparticipant. However, the relationship between the probability of $i^{\text {th }}$ household participant in SWC activities and the independent variables is not linear. In order to make meaningful interpretation, the probability of $i^{\text {th }}$ household being participant in SWC activities should to be written as linear combinations of explanatory variables. This was computed by taking natural log of equation 5 and we got

$$
L_{i}=\ln \frac{p_{i}}{1-p_{i}}=Z_{i}=\beta_{o}+\beta_{1} X_{i 1}+\beta_{2} X_{i 2}+\cdots \beta_{n} X_{i n}
$$

Where, $\mathrm{Li}$ is $\log$ of the odds ratio, which is linear not only in $\mathrm{X}$, but also in the parameters (the relationship between the probability of $i^{\text {th }}$ household being participant in SWC activities and his/her characteristics are linear now).

Thus, if the stochastic disturbance term (Ui) is introduced, the logit model becomes:

$Z_{i}=\beta_{0}+\beta_{1} X_{i 1}+\beta_{2} X_{i 2}+\cdots \beta_{n} X_{i n}+U_{i}$

In reality, the significant explanatory variables do not all have the same level of effect on the probability of farmers' participation in SWC activities. The relative effect of the significant explanatory variables can be measured by examining marginal effect, defined as the rate change in probabilities that would result from a unit change in the value of explanatory variable which can be computed using the following formula provided by (Gujirati, 2004)

$\frac{d P}{d X}=P(1-P) \beta_{i}$ .8

But after the logistic regression, STATA command ' $\mathrm{mfx}$ ' gives the value of marginal effect of each explanatory variable on the dependent variable and the interpretation of the significance variables in this study was based on marginal effect. In this study, the above econometric model was used to measure and analyze factors that affect farmers' participation in SWC activities.

Parameter estimation in logistic regression model: The logistic regression model cannot be estimated by the usual ordinary least square method because to apply OLS we must know the value of the dependent variable in (Pi / 1 - Pi), which obviously not known and more over the methods of OLS doesn't make any assumptions about the probabilistic nature of the disturbance term. If there is data on individual observations the method of maximum likelihood can be used to estimate the coefficients of the equation (Gujarati, 2004). Therefore, in this study the maximum likelihood estimation method was used to estimate the coefficients of parameters of the model. In line with this, descriptive statistics, such as mean, standard deviation, frequency, percentage, and chisquare test were employed to analyze data. Moreover STATA version 11.0 was employed for the analysis of the econometric model.

Multicolinearity test, Specification error test and Goodness-of-fit of the model were assessed to make valid the analysis.

Multicolinearity test: One of the assumptions of logistic regression model is that the independent variables are 
not linear combinations of each other. When this assumption violates that is when there is either an exact or approximately exact linear relationship among the independent variables, and it makes hard to get coefficient estimates with small standard error (Gujarati, 2004). Thus prior to the estimation of the logistic regression model, the explanatory variables were checked for the existence of multi-co-linearity.

The existence of multi-co-linearity among the continuous explanatory variables was checked using variance inflation factor (VIF). Following Gujarati (2004), VIF is defined as:

$\operatorname{VIF}\left(\mathrm{X}_{\mathrm{j}}\right)=\frac{1}{\left(1-\mathrm{R}_{\mathrm{j}}^{2}\right)}$

Where:

$\mathrm{Xj}=$ the $\mathrm{j}^{\text {th }}$ quantitative explanatory variable regressed on the other quantitative explanatory variables.

$R^{2} j$ = the coefficient of determination when the variable Xj regressed on the remaining explanatory variables. As a rule of thumb, if the VIF of a variable exceeds 10 that variable is said to be highly collinear and it can be concluded that multi-co-linearity is a problem (Gujarati, 2004).

Multi-co-linearity problem among discrete variables was detected using coefficient of contingency $(C C)$ calculated from chi-square. It is related to by the following formula as:

$C C=\sqrt{\frac{x^{2}}{N+x^{2}}}$

Where:

$\mathrm{x}^{2}=$ Chi-square random variable and

$\mathrm{N}=$ is total sample size.

Contingency Coefficient (CC) ranges from 0 to 1 . As rule of thumb, CC values less than 0.5 assumes weak association between discrete variables and indicates no severe multi-co-linearity.

Specification error test: The other assumption of logistic regression model is that the logit of dependent variable is a linear combination of the independent variables. When this assumption violates, there is a specification error in the model. This indicates that either the logit function is incorrect and/or all relevant variables are not included in the model. In this study the STATA command 'linktest' was used to detect a specification error of the model. This test is issued after the logit or logistic command and uses linear predicted value ( hat) and linear predicted value square (_hatsq) as a predictor for model specification error. As a rule of thumb to have no model specification error, the value of linear predictor (_hat) should be significant and that of the value of linear predictor square (_hatsq) should be insignificant in the linktest result. STATA output of logistic regression model gives the value of (_hat) and (_hatsq).

Goodness-of-fit of the model: The goodness of fit of a model measures how well the model describes the response variable. Assessing goodness of fit involves investigating how close values are predicted by the model with that of observed values (Bewick et al., 2005) cited in (Teshager 2012). Conventional measure of goodness of fit, $\mathrm{R}^{2}$, is not meaningful in binary regressed model but similar measures to $\mathrm{R}^{2}$ called pseudo $\mathrm{R}^{2}$ are available (Gugirati 2004). As a rule of thumb, if pseudo $R^{2}>0.2$ the model describes the response variable well.

Another alternative approach to test the significance of a number of explanatory variables is likelihood ratio test (LR). It tests the null hypothesis that all slop coefficients are simultaneously equal to zero (Gugirati 2004). Therefore, the likelihood-ratio test statistic is given by:

$$
\mathrm{LR}=\quad-2\left(\ln L_{0}-\ln L_{1}\right)
$$

Where, $\mathrm{L}_{0}$, is the likelihood function of the null model and, $\mathrm{L}_{1}$, is the likelihood function of the full model. Under the null hypothesis, LR statistics follows the $x^{2}$ distribution with degree of freedom equals to the number of explanatory variables and hence if LR exceeds $x^{2}(\alpha)$ we reject the null hypothesis and conclude that at least one of the independent variables is significantly related with participation in SWC activities. But STATA output of logistic regression gives the value of the log likelihood chi-square and pseudo R-square for the model and conclusion was made based on their values.

\section{Results and Discussions}

\subsection{Extent of Farmers' Participation in SWC Activities}

Major SWC works that were underway in the study area includes bunds, cut-off-drains and waterway; check dam construction, plantation on physical conservation structures and area closure etc (FWOA, 2013). Even though these structures have been implemented by farmers to address the soil erosion and water scarcity problems, the dimensions of farmers' participation in this activities was not the same and soil erosion is still severe in the study area (FWOA, 2013). In this study sample household was classified as a participant if he/she had participated in any of the soil and water conservation activities in terms of labor and finances or both on their own land. 
Table 8: Distribution of farmers' participation in SWC activities

\begin{tabular}{lclcc}
\hline Description & Active labor force & Percent & Sample HH head & Percent \\
\hline Participant & 423 & 32.87 & 194 & 50.92 \\
Non participant & 864 & 67.13 & 187 & 49.08 \\
Total & 1287 & 100 & 381 & 100 \\
\hline
\end{tabular}

Source: Own survey in March 2014

As we can see from the above (Table 8) on an average 49.08 percent (187) of the sample household heads did not participate in any of the soil and water conservation activities. Similarly, out of 1287 active labor forces (age from 15 - 64) of the sample household members, about 67.13 percent (864) didn't participate in any of the soil and water conservation activities.

Participated sample household heads were also asked whether they were participated in soil and water conservation activities voluntarily or not. As shown in (Table 9) below, out of 194 participated sample household heads, 70 percent (136) of them reported they were participated in the SWC works voluntarily. The remaining 30 percent (58) of household heads reported that they did SWC works simply because they were forced to do so by the government. This implies that out of 381 sample households, only 35.67 percent (136) of them were participated in soil and water conservation activities voluntarily in the study area.

Table 9: Participated farmers' willingness to participate in the SWC works in their own lands

\begin{tabular}{lcc}
\hline How are you participating in the SWC works currently & & Percent \\
underway in your land? & Frequency & 70 \\
\hline Voluntarily & 136 & 30 \\
Forced & 58 & 100 \\
Total & 194 & 100
\end{tabular}

Source: Own survey in March 2014

Out of 194 participated households in SWC works, only 7.7 percent of them were contributed both labor and finance by purchasing construction materials such as wood, stones etc. The rest 92.3 percent of the participated households contributed only labor for works. None of them was participated by contributed only money for soil and water conservation activities (Table 10). However, many literatures recommended that households' financial contribution is very essential for ensuring long-run interests of the stakeholders and the sustainability of the soil and water conservation structures.

Table 10: Contribution of the participated sample HHs in soil and water conservation works

\begin{tabular}{llc}
\hline Contribution & Frequency & Percent \\
\hline Financial only & 0 & 0 \\
Labor only & 179 & 92.3 \\
Both labor and finance & 15 & 7.7 \\
Total & 194 & 100 \\
\hline
\end{tabular}

Source: Own survey in March 2014

Attempts have also made to assess farmers' participation level in soil and water conservation activities using participation index formula. Activities such as bunds, cut-off-drains and waterway, check dam construction, plantation on physical conservation structures, and area closures were considered to assess the extent of farmers' participation in the soil and water conservation activities. Participation index of each sample households was computed as the ratio of summation of the number of SWC activities he/she done to the total number of SWC activities that were considered to assess the extent of farmers participation (bunds, cut-offdrains and waterway, check dam construction, plantation on physical conservation structures, and area closures) in the study area.

Table.11: Distribution of participation index of sample households in SWC activities

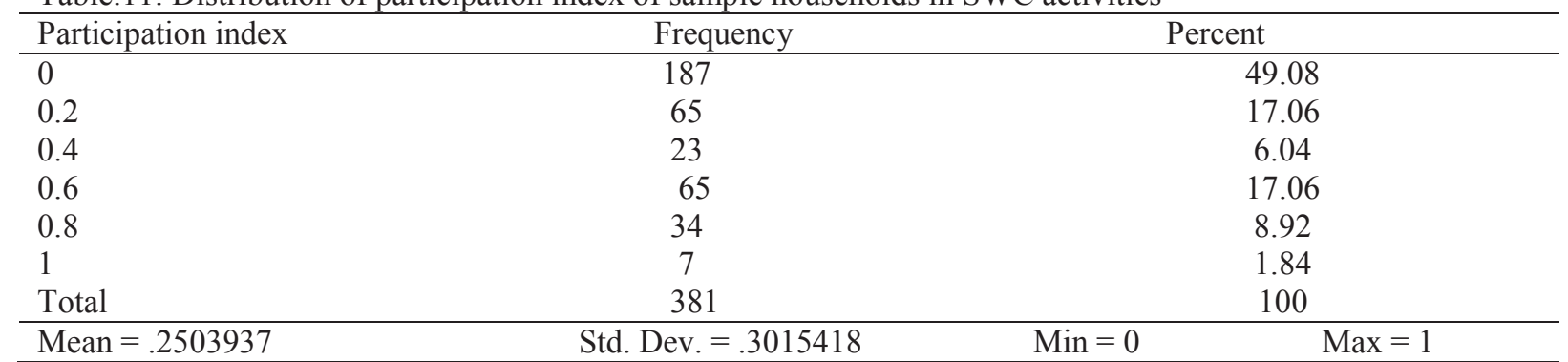

Source: Own survey in March 2014

Participation index of the sample households revealed that the indices lie between 0 and 1 . The zero indexes indicate no participation in SWC activities and one index indicates households participated in all the soil and 
water conservation activities. About 49.08 percent of the respondents did not participate in any of the soil and water conservation activities, only 1.8 percent of them were did all the SWC activities. Participation index 0.2 . 0.4, 0.6 and 0.8 indicates the participation of households in one, two, three and four SWC activities respectively. The overall mean of participation index of sample households was found to be 0.25 with standard deviation of 0.302 .

\subsection{Descriptive Analysis of the Determinants of Households' Participation in SWC Activities}

In this sub topic the major factors that expected to affect farmers' participation in soil and water conservation activities were analyzed below using descriptive statistics (Pearson chi ${ }^{2}$ statistics).

1. Relationship of participation in SWC activities with age of household head Table.12: Associations between participation in SWC activities and household head age

\begin{tabular}{lccc}
\hline Age category & None participant(187) & Participant (194) & Total (381) \\
\hline Youth & 13.9 & 9.28 & 11.55 \\
Adult & 76.47 & 82.47 & 79.53 \\
Old & 9.63 & 8.25 & 8.92 \\
Total & 100 & 100 & 100 \\
\hline
\end{tabular}

Pearson chi $^{2}=2.3982 \quad(\mathrm{Pr}=0.301)$

Source: Own survey in March 2014

In this study it was hypothesized that older age of the household head are more likely to participate in SWC activities. The result revealed that 11.55 percent found to be youths, of which 13.9 percent were from none participant groups in soil and water conservation activities and 9.28 percent were from participant groups in soil and water conservation activities. Similarly 79.53 percent of sample households found to be in adult category and none participant groups in soil and water conservation activities accounted 76.47 percent and participant groups in soil and water conservation activities accounted 82.47 percent from this category. This implies that participant in soil and water conservation activities and age of the household head have positive relationship. But the value of Pearson chi ${ }^{2}$ indicated that the age of the household head was found to be statistically insignificant even at 10 percent probability level in participation of SWC activities as presented in above (Table 12).

2. Relationship of participation in SWC activities with education level of household head Table.13: Associations between participation in SWC activities and education level of head

\begin{tabular}{llll}
\hline Education level & None participant (187) & Participant (194) & Total (381) \\
\hline Illiterate & 50.27 & 26.8 & 38.32 \\
W and reading & 37.98 & 49.48 & 43.83 \\
Grade 1-4 & 7.49 & 12.89 & 10.24 \\
Grade 5-8 & 3.2 & 10.31 & 6.82 \\
Grade 9-10 & 1.06 & 0.52 & 0.79 \\
Total & 100 & 100 & 100 \\
\hline
\end{tabular}

Source: Own survey in March 2014

In this study it was hypothesized that educated household heads may understand, analyze, and interpret the advantage of soil and water conservation more easily than uneducated household heads and therefore education and participation of households in soil and water conservation expected to relate positively and significantly. The survey result revealed that none participant groups in SWC activities accounted 50.27 percent and participant groups accounted 26.8 percent from 38.32 percent of illiterates (household heads who cannot read and write). On the other hand, proportion of educated household head in participant groups were higher than in none participant groups in all levels of educated household heads and percentage proportion of participant households increase with increase in education level. This implies that increase in education level of the household heads will increase their participation in soil and water conservation activities. As shown in (Table 13) value of Pearson $\mathrm{chi}^{2}$ also indicated that education level was a significant variable that create variation in participation level of the households in soil and water conservation activities in the study area. It was found to be statistically significant at1 percent probability level and there is a positive association between participation in SWC activities and education level of the household head as expected. 
3. Relationship of participation in SWC activities with extension visit of household head

Table.14: Associations between participation in SWC activities and extension visit per year

\begin{tabular}{cccc}
\hline No of visit & None participant (187) & Participant (194) & Total (381) \\
\hline 0 & 55.08 & 29.9 & 42.26 \\
1 & 10.7 & 15.46 & 13.12 \\
2 & 13.9 & 19.59 & 16.8 \\
3 & 9.6 & 13.92 & 11.81 \\
4 & 5.88 & 8.76 & 7.35 \\
5 & 3.2 & 8.25 & 5.77 \\
6 & 1.1 & 0.52 & 0.79 \\
7 & 0 & 1.03 & 0.52 \\
8 & 0.53 & 2.06 & 1.13 \\
12 & 0 & 0.52 & 0.26 \\
Total & 100 & 100 & 100 \\
\hline
\end{tabular}

Source: Own survey in March 2014

Number of extension visit per year expected to be associated positively with the households' participation in soil and water conservation activities. Extension services were provided by development agents in the study area. They are expected to provide the necessary information to acquire new skills and knowledge to farmers to enhance their participation in soil and water conservation activities. The study showed that sample households had a mean of 1.6 visits per a year from extension agents. The maximum and the minimum number extension visits of sample households were 12 and 0 per a year respectively with standard deviation of 1.90106 .

As shown in (Table 14) value of Pearson chi $^{2}$ indicated that extension visit was a significant variable that create variation in participation level of the households in soil and water conservation activities in the study area. It was found to be statistically significant at 1 percent probability level and there is a positive association between participation of households in SWC activities and extension visit as expected.

\subsection{Econometric Analysis of Factors Affecting Farmers' Participation in SWC Activities}

To identify factors that expected to affect farmers' participation in soil and water conservation activities, binary logistic regression model was used. Based on information from the related literature and the researcher's personal knowledge regarding the study area and conditions of farmers, variables that were expected to affect farmers participation in SWC activities includes age (AGE), family size (FAS), education level (EDU), livestock holding (TLU), cultivated farm land (CFL) and extension contact (EXC) of the sample household head.

The six variables hypothesized to affect farmers' participation in SWC activities were entered to the logistic regression model using STATA 11 software. Among the variables family size, education level of household heads, livestock owned, and cultivated farm land of the household head were found to be statistically significantly to affect farmers participation in SWC activities the in the study area. But the coefficient of family size of the household head was found to be negative which was in contrary to the prior expectation. The remaining two variables age and extension contact were found to have correct signs but insignificant relationship with farmers participation in SWC activities in the study area (see Table 22). But extension visit was significant in descriptive part of the analysis.

Table 22: The estimated binary logistic regression results of farmers, participation in SWC

\begin{tabular}{|c|c|c|c|c|c|c|c|}
\hline $\log$ & Likelihood & $=$ & -209.44 & & $\begin{array}{l}\text { Number } \\
\text { LR chi2 } \\
\text { Prob } \\
\text { Pseudo }\end{array}$ & $\begin{aligned} \text { of obs } & = \\
& = \\
>\operatorname{chi} 2 & = \\
\mathrm{R} 2 & =\end{aligned}$ & $\begin{array}{l}381 \\
108.7 \\
0.000 \\
0.206 \\
\end{array}$ \\
\hline variables & Coef. & Std. Err. & $\mathrm{Z}$ & $\mathrm{P}>\mathrm{Z}$ & [95\%Conf. & Interval] & marginal effect \\
\hline AGE & -0.011105 & 0.011398 & -0.97 & 0.330 & -0.03345 & 0.011236 & -0.0027557 \\
\hline FAS & -0.254571 & 0.076411 & -3.33 & $0.001 * * *$ & -0.40433 & -0.10481 & -0.0631728 \\
\hline EDU & 0.282675 & 0.144347 & 1.96 & $0.050 * *$ & -0.00024 & 0.56559 & 0.070147 \\
\hline TLU & 0.4359438 & 0.097481 & 4.47 & $0.000 * * *$ & 0.244884 & 0.627003 & 0.1081813 \\
\hline CFL & 2.373924 & 0.502119 & 4.73 & $0.000 * * *$ & 1.389789 & 3.358059 & 0.5890991 \\
\hline EXC & 0.0456236 & 0.075204 & 0.61 & 0.544 & -0.10177 & 0.193021 & 0.0113217 \\
\hline
\end{tabular}

$* * *$ and $* *$ indicates significance at 1 and 5 percent level respectively.

Source: Own survey in March 2014. 
Before the actual implementation of the above model, logistic regression diagnostics of the model were considered. This includes multicolinearity test, specification error test and goodness-of-fit.

Problem of multi-co-linearity have been checked the presence of high co-linearity between explanatory variables using variance inflating factor for continuous variables. As it is shown in the (Table 23), value of variance inflation factors (VIF) of all continuous explanatory variables were less than 2 with mean of 1.37 . Therefore problem of multi-co-linearity was not serious among continuous independent variables because of VIF value for all the variables were found less than 10. Thus each independent continuous variable could have independent influence on farmers' participation in soil and water conservation activities.

Table 23: Variance inflating factors for independent variables of farmers' participation in SWC

\begin{tabular}{l|cc}
\hline Variable & VIF & 1/VIF \\
\hline CFL & 1.69 & 0.591 \\
TLU & 1.63 & 0.613 \\
EXC & 1.28 & 0.78 \\
AGE & 1.22 & 0.818 \\
FAS & 1.22 & 0.819 \\
EDU & 1.17 & 0.852 \\
\hline Mean VIF & 1.37 & \\
\hline Source: Own survey in March 2014.
\end{tabular}

Source: Own survey in March 2014.

Linktest was employed to detect specification error of the model using STATA version-11 software. This test uses linear predicted value ( hat) and linear predicted value square ( hatsq) as a predictor for model specification error. To have no model specification error, the value of linear predictor (_hat) should be significant and the value of linear predictor square (_hatsq) should be insignificant in the linktest result. The test result showed that the variable (-hat) was found to be significant (with p-value $=0.000$ ) and variable $(-$ hatsq) found to be insignificant (with $p$-value $=0.22$ ). This result revealed that we have chosen meaningful predictors and there was no specification error in the logistic regression model of factors affecting farmers' participation in SWC activities (Table 24).

Table 24: Result for model specification diagnosis for farmers' participation in SWC activities

\begin{tabular}{|c|c|c|c|c|c|c|c|}
\hline \multirow{3}{*}{\multicolumn{2}{|c|}{ Logistic }} & \multirow[t]{3}{*}{ Regression } & & Number of obs & $=$ & 381 & \\
\hline & & & & LR $\operatorname{chi} 2(2)$ & $=$ & 110.29 & \\
\hline & & & & Prob $>$ chi 2 & $=$ & 0.000 & \\
\hline Log likelihood & $=$ & -208.64816 & & Pseudo R2 & $=$ & 0.209 & \\
\hline SWCP & & Coef. & Std. Err. & $\mathrm{z}$ & $\mathrm{P}>\mathrm{Z}$ & [95\%Conf. & Interval] \\
\hline _hat & & 0.9635186 & 0.12196 & 7.90 & 0.00 & 0.7244743 & 1.202563 \\
\hline _hatsq & & 0.1052535 & 0.08493 & 1.24 & 0.22 & -0.0612125 & 0.27172 \\
\hline cons & & -0.1067005 & 0.14613 & -0.73 & 0.47 & -0.3931126 & 0.179712 \\
\hline
\end{tabular}

Source: Own survey in March 2014.

After fitting the logistic regression model, the value of measure of goodness-of-fit called pseudo $\mathrm{R}^{2}$ was also assessed. As a rule of thumb, if pseudo $R^{2}>0.2$ then we can conclude that the model describes the response variable well. In estimated binary logistic regression results (Table 22) the value of pseudo $R^{2}$ found to be greater than 0.2. This indicates that the independent variables describe farmers' participation in SWC activities well in the model.

Another alternative approach to test the overall fit of the logistic regression mode is likelihood ratio test (LR). As showed in the STATA output of logistic regression (Table 22) likelihood ratio test statistic was found to be $(\mathrm{LR})=\mathbf{1 0 8 . 7}$ which is distributed as chi-square with 6 degree of freedom and the tabulated value found to be $\boldsymbol{x}^{2}{ }_{\mathbf{0 . 0 5}}(\mathbf{6})=\mathbf{1 2 . 5 9 1 6}$ in the table. Thus, since value of LR exceeds value of $\boldsymbol{x}^{2}(6)$, we reject the null hypothesis and conclude that at least one of the independent variables is significantly related with farmers' participation in SWC activities at five percent significant level.

After checking the healthiness of the model, econometric result interpretation of significant variables that affect farmers' participation in SWC activities was presented as showed bellow.

Family size (FAS): The result of the logistic regression mode showed a negative relationship between family size of the household and participation of household head in SWC activities and was statistically significant at 1 percent of significance level. This implies that the probability of participating of the hous ehold head in soil and water conservation activities decreases with an increase in family size. Holding other explanatory variables 
constant, each additional member of the household decreases the probability of participation of household head in soil and water conservation activities by 6.3 percent which is contrary with the hypothesis made in this research. This may be because as member of the household increase piece of land seem not enough to support the families and they may think that soil and water conservation structures take some land out of production. During interview, some farmers also reported that they were discouraged to participate in SWC activities because the bunds take some land out of production and cause to loss their farm land.

Education level of HH head (EDU): As the model output showed, there was a positive relationship between education level of the household head and participation of the household head in SWC activities. The variable took the expected sign and it was statistically significant at 5 percent of significance level. Holding other explanatory variables constant, changing the household head education level by one unit could increase the probability of participation of household head in soil and water conservation activities by 7 percent. The possible explanation for this finding was that most of the educated household heads are conscious about land degradation and may show interest to participate in soil and water conservation activities. Educated household could also accept technical advice from extension workers, and can easily obtain, understand and process the benefit of participating in soil and water conservation activities.

Livestock owned (TLU): The result of the logistic regression analysis showed that the coefficient of the livestock holding of the household head is statistically significant at 1 percent probability level and positively related to households' participation in soil and water conservation activities. This implying that the likelihood of a households' becoming participant in SWC activities can increases with an increase in the livestock in TLU. The result indicates that holding other variables constant, increase in livestock of the household head by one TLU can increase the probability of household heads' participation in SWC activities by 10 percent. The justification of this result is that because the enhancement of soil and water conservation activities on his/her own private land will lead to the opportunity to get fodder sources and water for his/her livestock.

Cultivable farm land (CFL): As expected, area of cultivated land positively influenced the probability of the participation of household head in soil and water conservation activities in the study area. The variable was statistically significant at 1 percent level of significance. The results of the binary logistic regression model showed that an increase in cultivable land of the household head by one hectare, can increases the probability of their participation in SWC activities by 58.9 percent being other independent variables which were included in the logistic regression model constant. The possible explanation for this result may be that soil and water conservation structures which take some land out of production could not be a major problem for household heads when she/he have more cultivable farm land.

\section{Conclusions}

The descriptive result of this study showed that only 35.67 percent of sample households participated in soil and water conservation activities voluntarily and it can be conclude that voluntary participation of farmers' in SWC activities was low in the study area which was affected by family size negatively and education level of the head, livestock holding and cultivated land size positively as showed in logistic regression output.

The positive marginal effect of size of cultivated land on farmers' participation in soil and water conservation found to be higher than other significant variables. Farmers who have larger cultivated land holding are more likely to participate in soil and water conservation activities. Therefore it can be conclude that cultivated land size is the most determinant factor for farmers' participation in soil and water conservation activities in the study area.

\section{Reference}

Abera Birhanu, 2003. Factors Influencing the Adoption of Introduced Soil Conservation Practices in Northwestern Ethiopia, Discussion paper, Institute of Rural Development, University of Goettingen

Adugna, A., Abegaz, A., and Cerdà, A. (2015). Soil erosion assessment and control in Northeast Wollega, Ethiopia. Solid Earth Discuss, 7(4), 3511-3540. doi: 10.5194/sed-7-3511-2015

Amsalu, A., and De Graaff, J. 2006. Determinants of adoption and continued use of stone terraces for soil and water conservation in the Ethiopian highland watershed. Ecological Economics. In press.

Badal, P.S., Pramod Kumar and Geeta Bisaria, 2006. Dimensions and Determinants of Peoples' Participation in Watershed Development Programmes in Rajasthan. Agricultural Economics Research Review. Vol. 19. January-June, 2006: 57-69.

Bezuayehu Tefera, Gezahegn Ayele, Yigezu Atnafe, Jabbar M.A. and Paulos Dubale. 2002. Nature and causes of land degradation in the Oromiya Region: A review. Socio-economics and Policy Research Working Paper 36. ILRI (International Livestock Research Institute), Nairobi, Kenya. 82 pp.

Endalamaw Assefa, 2013. "Determinants of Agricultural Productivity in Dera Wored, South Gondar Zone of the Amhara National Regional State, Ethiopia.” Unpublished M.Sc. Thesis, Gondar University.

Farata Woreda Office of Agriculture, 2013. Unpublished report 
Gete Z, Menale K, Pender J and Mahmud Y (2006). Stakeholder Analysis for Sustainable Land Management (SLM) in Ethiopia: Assessment of Opportunities, Strategic Constraints, Information Needs, and Knowledge Gaps. Environmental Economics Policy Forum for Ethiopia (EEPFE). pp4-91.

Girma T (2001). Land Degradation: A Challenge to Ethiopia. International Livestock Research Institute, Addis Ababa, Ethiopia. pp815-823.

Gujarati, D. N., 2004. Basic Econometrics, 4th ed. New York: The McGraw-Hill Inc.

Hilina Mikrie, 2005. "Dimension and Determinant of Poverty in Pastoral Areas of Eastern Ethiopia: The Case of Shinile Zone in Somalia National Regional State." Unpublished M.Sc. Thesis, Alemaya University.

Hurni H, Solomon A, Amare B, Berhanu D, Ludi E, Portner B, Birru Y and Gete Z (2010). Land degradation and sustainable land management in the highlands of Ethiopia. In Hurni H, Wiesmann U (ed) with an international group of co-editors. Global change and sustainable development: A synthesis of regional experiences from research partnerships. Georaphica Bernensia. 5:187-201.

Kouelo Alladassi Felix, Houngnandan Pascal, Azontonde Hessou Anastase, Dedehouanou Houinsou and Gangnon Semevo Oslo Armel, 2015. Farmers' Perceptions on Soil Degradation and Their Socioeconomic Determinants in Three Watersheds of Southern Benin, Journal of Biology, Agriculture and Healthcare, Vol.5, No.22,

Nigussie Haregeweyn, Atsushi Tsunekawa, Jan Nyssen, Jean Poesen, Mitsuru Tsubo, Derege Tsegaye Meshesha, Brigitta Schutt, Enyew Adgo and Firew Tegegne, 2019. Soil erosion and conservation in Ethiopia: A review. Available from: https://www.researchgate.net/publication/282895993_Soil_erosion_and_conservation_in_Ethiopia_A_revie $\mathrm{W}$

Oluwole Matthew and Ejovwoke UMUKORO, 2011. Farmers' Perception of the Eff ects of Land Degradation on Agricultural Activities in Ethiope East Local Government Area of Delta State, Nigeria, Agric. conspec. sci. Vol. 76 No. 2

Paulos D (2001). Soil and water resources and degradation factors affecting their productivity in the Ethiopian highland agro-ecosystems. Michigan State University Press. 8(1): 1-18.

Sui J., He Y., and Liu C. 2009, Changes in sediment transport in the Kuye River in the Loess Plateau in China. International Journal of Sediment Research, Vol. 24, pp. 201-213.

Tesfa Worku and Sangharsh Kumar, 2016. Farmer's Perception on Soil Erosion and Land Degradation Problems and Management Practices in the Beressa Watershed of Ethiopia. Journal of Water Resources and Ocean Science. Vol. 5, No. 5, 2016, pp. 64-72. doi: 10.11648/j.wros.20160505.11

Teshager Zerihun, 2012. "Multilevel Logistic Regression Analysis of Correlation of Diarrhea Among Infants in Ethiopia.” Unpublished M.Sc. Thesis, Hawasa University. 